\title{
Exploring frontiers of the mind-brain relationship
}

Alexander Moreira-Almeida \& Franklin Santana Santos. Springer: New York, 2012.

Five reasons to read Exploring frontiers of the mind-brain relationship by Alexander Moreira-Almeida \& Franklin Santana Santos.

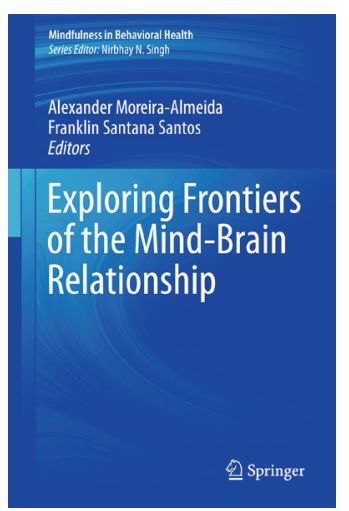

\section{The book's theme}

The book's theme is widely interesting. Hardly anyone in contact with the human mind won't be interested in the mind-brain relationship. Whether a lay person, a practitioner or researcher, or out of mere curiosity, that person will certainly be drawn to the book. It is an invitation to satisfy our curiosity about the mysteries of the human mind.

\section{The editors}

The editors are two respected teachers and researchers in the area covered by the book. Alexander Moreira-Almeida is a psychiatrist and has stood out in Brazilian science by daring to study the issue of spirituality in a serious and straightforward way, attempting to escape from reductionism, as this book shows very well. Franklin Santana Santos is a geriatrist and has led studies about death, dying and palliative care in Brazil. He has already published several papers and books on that matter.

\section{The contributors}

The book has a series of reputed international contributors. One of the highlights is the moving preface by Claude Robert Cloninger, renowned professor of Psychiatry, Psychology and Genetics, quite well known among psychiatrists for the development of instruments for the assessment of personality: the Tridimensional Personality Questionnaire (TPQ) and the Temperament and Character Inventory ( $\mathrm{TCl})$. Also noteworthy is the contribution of Deepak Chopra, author of countless "best-sellers" in fiction and non-fiction about the mind-body relationship, spirituality and peace.

\section{The structure of the book}

The idea of writing this book arose in an international symposium led by the editors. The book's structure intends to bring to the reader an approach of the mind-brain relationship that moves beyond the materialistic reductionism. With that in mind, the authors chose to divide the book in four parts: Philosophy and History; Physics; Functional Neuro-imaging and Human Experience, as promising avenues for the investigation of the mind-brain relationship. That division gives us a fine glimpse on the complexity and the depth, as well as how the theme will be approached.

\section{The Publisher}

The book's publishing by an international Publisher in English is an indication of its quality. The editors and the contributors must be complimented for this achievement for Brazilian scientific literature. As I see it, the publishing of this book in English is itself already a great sign of success.

Neusa Sicca da Rocha

Professora do Programa de Pós-Graduação em Psiquiatria Universidade Federal do Rio Grande do Sul 